\title{
A Pancreatic Fistula after the Laparoscopic Sleeve Gastrectomy
}

\author{
Gökhan Selçuk Özbalcı, ${ }^{1}$ Ayfer Kamalı Polat, ${ }^{1}$ İsmail Alper Tarım, ${ }^{2}$ Murat Derebey, ${ }^{1}$ \\ Mehmet Selim Nural, ${ }^{3}$ Volkan Tümentemur, ${ }^{1}$ and Ufuk Karabacak ${ }^{1}$ \\ ${ }^{1}$ Department of General Surgery, Faculty of Medicine, Ondokuz Mayıs University, 55139 Samsun, Turkey \\ ${ }^{2}$ Department of General Surgery, Varto State Hospital, 49100 Muş, Turkey \\ ${ }^{3}$ Department of Radiology, Faculty of Medicine, Ondokuz Mays University, 55139 Samsun, Turkey
}

Correspondence should be addressed to Gökhan Selçuk Özbalc1; drselcuk917@yahoo.com

Received 11 January 2015; Revised 2 March 2015; Accepted 24 April 2015

Academic Editor: Yasushi Rino

Copyright (C) 2015 Gökhan Selçuk Özbalcı et al. This is an open access article distributed under the Creative Commons Attribution License, which permits unrestricted use, distribution, and reproduction in any medium, provided the original work is properly cited.

Laparoscopic sleeve gastrectomy (LSG) is a popular surgical weight-loss procedure in the treatment of morbid obesity. There are some complications regarding this procedure in the literature. This report presents a pancreatic fistula (PF) case, which has not been previously seen.

\section{Background}

Laparoscopic sleeve gastrectomy (LSG) has recently become a popular method of surgical treatment for morbid obesity [1]. This technique is superior due to the fact that it does not disturb the integrity of the gastrointestinal system; it contains no external material and has low complication ratios [2]. The most common complications of LSG are leakage (2.2\%) and suture line bleeding $[3,4]$.

Pancreatic fistula (PF), post-LSG, so far has not been reported. PF mostly develops after pancreatic disorders or as a result of trauma, such as pancreatic surgery, abdominal trauma, or percutaneous radiologic procedures. In addition, it has been reported that pancreatic fistula may develop after surgery involving adjacent organs [5]. We, however, report a post-LSG pancreatic fistula case, which does not yet exist in the literature.

\section{Case Presentation}

A 43-year-old morbidly obese man underwent LSG in another hospital 32 days prior to admittance to our hospital. Patient's height was 179 centimeters, body weight was 160 kilograms, and body mass index (BMI) was $50 \mathrm{~kg} / \mathrm{m}^{2}$. There were no additional disease and no comorbidity. After the sixth day of his operation, the patient was suffering from $39^{\circ} \mathrm{C}$ fever and a spit-like accumulation of $100 \mathrm{~mL} /$ day from the 22 French silicon drain located near his stomach. The initial suspicion was that there could be a stapler line leakage. Therefore, the patient was not discharged and was observed further in the following 25 days. Fluid accumulation in the patient's drain did not decrease. An endoscopic stent was applied twice; however, the procedures were a failure.

After this experience, the patient demanded to be discharged from the hospital and admitted to our institution. He did not have oral intake. His initial fever was $36.9^{\circ} \mathrm{C}$, his tension was $120 / 80$, his pulse was 88 beats/min, his $\mathrm{Hb}$ was $15.1 \mathrm{~g} / \mathrm{dL}$, his WBC was $8.27 / \mathrm{mm}^{3}$, his Plt was $331 / \mathrm{mm}^{3}$, his amylase was $460 \mathrm{U} / \mathrm{L}$, and his lipase was $208 \mathrm{U} / \mathrm{L}$. Initially, a leakage test using methylene blue was conducted on the patient and no fluid in the drain was observed. Then, oral-intravenous contrasted computer tomography (CT) was performed. The drain was seen along the stapler line and there was no leakage on the CT examination.

A minimal pollution was observed between the stomach and pancreas. It was considered a postoperative change and a pathological case was not considered (Figure 1). Meanwhile, $30-100 \mathrm{~mL} /$ day fluid was continuously discharged by the drain. On the fifth day of our clinical follow up, a new oral contrasted dynamic CT was performed due to the suggestion from the radiology department. There was no leakage observed in that test either. As a result, it was suspected 


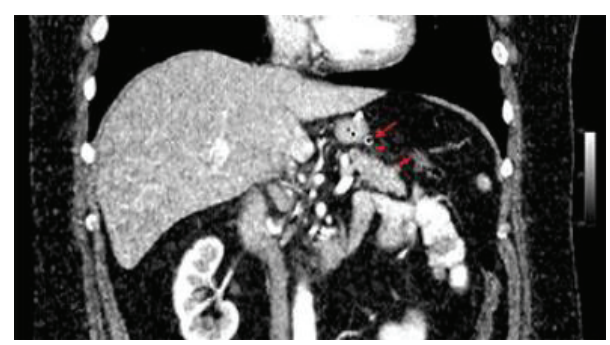

FIGURE 1: Long arrow: the drain; short arrow: pancreatic corpus; arrow head: focal contamination on the fatty tissue between the pancreas and drain.

that a pancreatic fistula may have occurred in the patient. Thus, drain and spit fluid were sent to the laboratory and examined for amylase level. The spit fluid amylase level was $297.900 \mathrm{U} / \mathrm{L}$ and the drain amylase was $61.499 \mathrm{U} / \mathrm{L}$. The drain amylase level led us to believe that there was a pancreatic fistula in the patient. Upon this observation, octreotide, a somatostatin analogue, was started with the subcutaneous dosage of $3 \times 0.1 \mathrm{mg} / \mathrm{mL}$ [6]. The patient dramatically responded to the treatment. After 48 hours, fluid accumulation from the drain stopped and oral intake was started. The treatment continued in the following three days. Additionally, intravenous medication consists of 3500 $\mathrm{cc} /$ day total parenteral nutrition, $40 \mathrm{mg} /$ day omeprazole, and $60 \mathrm{mEq}$ /day potassium chloride, which was given until oral intake started. Also $7500 \mathrm{IU} / 0,3 \mathrm{~mL} /$ day bemiparin sodium was given as long as the patient was hospitalized. On the 12th day after the patient was admitted to our clinical, his blood test results were as follows: $\mathrm{Hb}: 12.7 \mathrm{~g} / \mathrm{dL}, \mathrm{WBC}: 5.9 / \mathrm{mm}^{3}$, Plt: 291/ $\mathrm{mm}^{3}$, amylase: $138 \mathrm{U} / \mathrm{L}$, and lipase: $107 \mathrm{U} / \mathrm{L}$. The patient's drain was uninstalled on the 12th day and he was discharged on the 13th day. Further follow-ups and tests on the patient in the following year showed that he had no further complaints.

\section{Discussion}

It is estimated that there are over 300 million obese adults in the world [7]. Obesity should not be seen as only a cosmetic problem due to its association with increased risk of type II diabetes, hypertension, cardiovascular disease, dyslipidemia, nonalcoholic steatohepatitis, arthritis, choledolithiasis, sleepapnea syndrome, and many types of cancer [8].

People with a BMI of 40 or greater, who have tried diet and exercise, who do not have an endocrine disease, who are not addicted to alcohol or drugs, and who are psychologically stable, are candidates for bariatric surgery. Additionally, patients with a BMI of 35 to $40 \mathrm{~kg} / \mathrm{m}^{2}$ for weight-loss who are expected to improve type 2 diabetes, cardiorespiratory diseases, and obesity-related conditions, such as severe joint disease and serious psychological disorders, are suitable for bariatric surgery [9].

Weight-loss and metabolic effects in patients who have undergone LSG can be achieved by a reduction in the stomach volume capacity and thus a reduction in food intake, as well as mechanical and hormonal changes. LSG has also

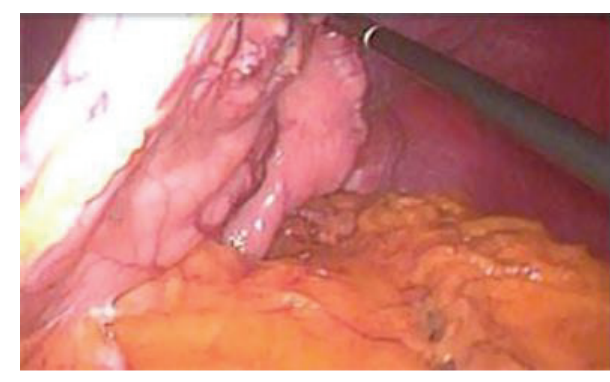

FIgURE 2: Elevation of the stomach.

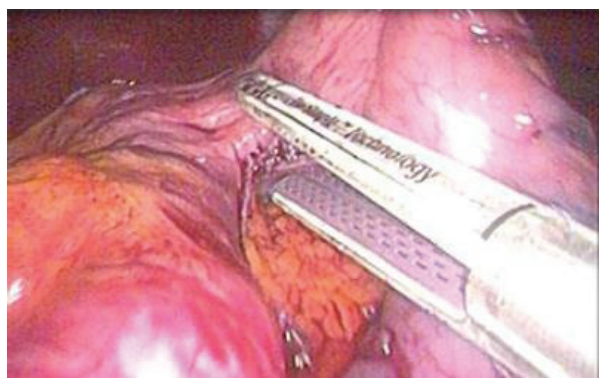

FIGURE 3: Placing stapler's blunt and thick side facing down.

low mortality and morbidity, and its short-term results are very effective for appropriate patients with a BMI of $40 \mathrm{~kg} / \mathrm{m}^{2}$ or greater who instituted but failed an adequate exercise and diet program. The most common complications are leakage and bleeding from the suture line [1-4]. However, a PF after LSG is a complication that has not been encountered in the literature. In our critical opinion, we suspected a minimal injury caused by anatomical closeness in our patient who was operated on in another hospital. The location of the drain on a major curvature through the pancreas provided drain leakage and avoided the development of peritonitis. Efficiently providing drainage prevented the radiologic observation of fluid accumulation around the pancreas. At the same time, although the patient had the operation long time ago and the drain index was not as expected, pancreatic markers were reasonably high.

\section{Conclusion}

LSG is an efficient surgical technique for patients suffering from morbid and super morbid obesity. There are a few important ways to avoid complications during LSG. The first one is to elevate the stomach during dissection with ligaSure and to check the posterior face in every state as shown in Figure 2. The second way is by placing the stapler's blunt and thick side facing down and there must be a clear vision of what is in the stapler branches. Thus, we believe that the surrounding solid organs and vessel structures will be protected (Figure 3). The last point is that, before the firing of the stapler, the stomach should be hanged and checked, and, thus, the lower leg of the stapler should not touch any organs. Additionally, we have to make sure that there is no tissue between the legs of the stapler in order for the operation to be 
conducted securely. However, despite the present case report, a PF is an extremely rare short-term side effect in patients with LGS.

\section{Conflict of Interests}

The authors declare that there is no conflict of interests regarding the publication of this paper.

\section{References}

[1] B. Wölnerhanssen and R. Peterli, "State of the art: sleeve gastrectomy," Digestive Surgery, vol. 31, no. 1, pp. 40-47, 2014.

[2] A. A. Gumbs, M. Gagner, G. Dakin, and A. Pomp, "Sleeve gastrectomy for morbid obesity," Obesity Surgery, vol. 17, no. 7, pp. 962-969, 2007.

[3] G. Ogunc, "Laparoscopic sleeve gastrectomy: weight loss and metabolic effectiveness," Turkiye Klinikleri Journal of General Surgery Special Topics, vol. 5, pp. 17-24, 2012.

[4] M. Parikh, R. Issa, A. McCrillis, J. K. Saunders, A. UdeWelcome, and M. Gagner, "Surgical strategies that may decrease leak after laparoscopic sleeve gastrectomy: a systematic review and meta-analysis of 9991 cases," Annals of Surgery, vol. 257, no. 2, pp. 231-237, 2013.

[5] O. Le Moine, C. Matos, J. Closset, and J. Devière, "Endoscopic management of pancreatic fistula after pancreatic and other abdominal surgery," Best Practice and Research: Clinical Gastroenterology, vol. 18, no. 5, pp. 957-975, 2004.

[6] E. Lermite, D. Sommacale, T. Piardi et al., "Complications after pancreatic resection: diagnosis, prevention and management," Clinics and Research in Hepatology and Gastroenterology, vol. 37, no. 3, pp. 230-239, 2013.

[7] P. T. James, N. Rigby, R. Leach, and International Obesity Task Force, "The obesity epidemic, metabolic syndrome and future prevention strategies," European Journal of Cardiovascular Prevention and Rehabilitation, vol. 11, no. 1, pp. 3-8, 2004.

[8] D. W. Haslam and W. P. T. James, “Obesity," The Lancet, vol. 366, no. 9492, pp. 1197-1209, 2005.

[9] M. Fried, V. Hainer, A. Basdevant et al., "Interdisciplinary European guidelines on surgery of severe obesity," Obesity Facts, vol. 1, no. 1, pp. 52-59, 2008. 


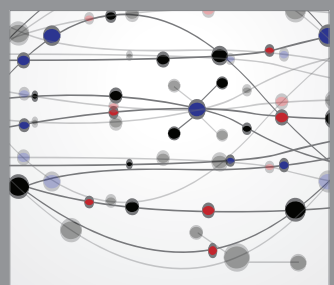

The Scientific World Journal
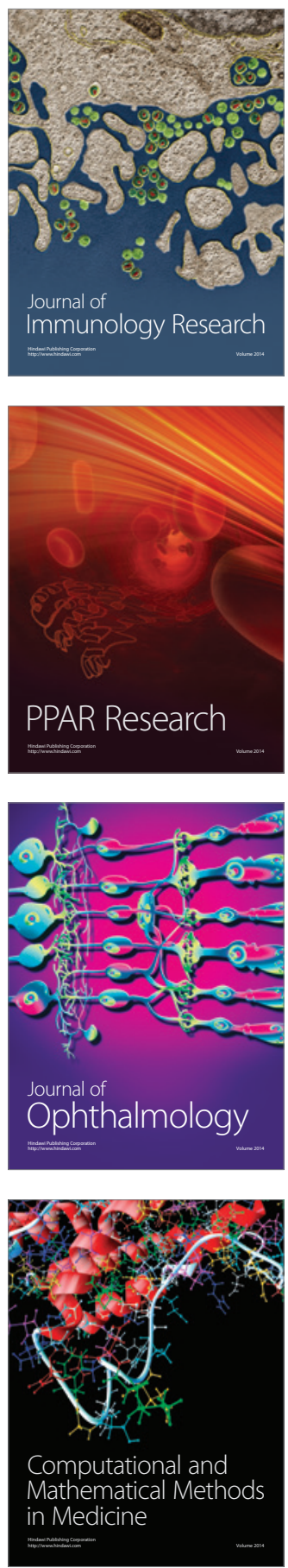

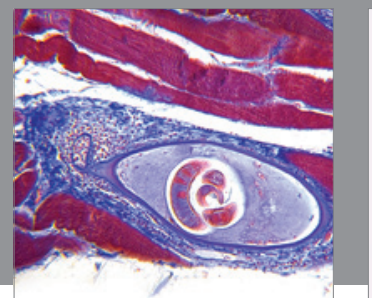

Gastroenterology

Research and Practice
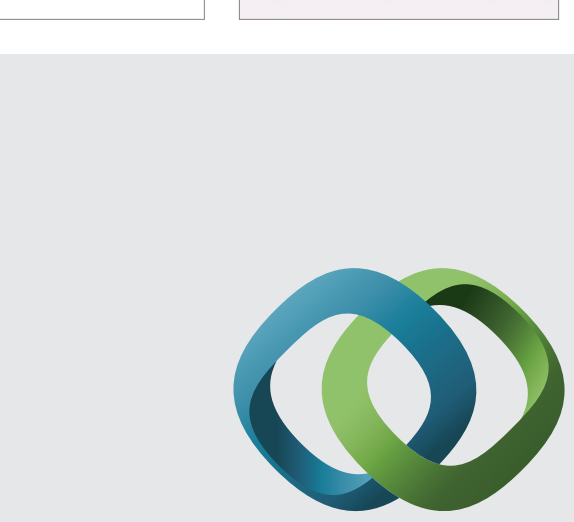

\section{Hindawi}

Submit your manuscripts at

http://www.hindawi.com
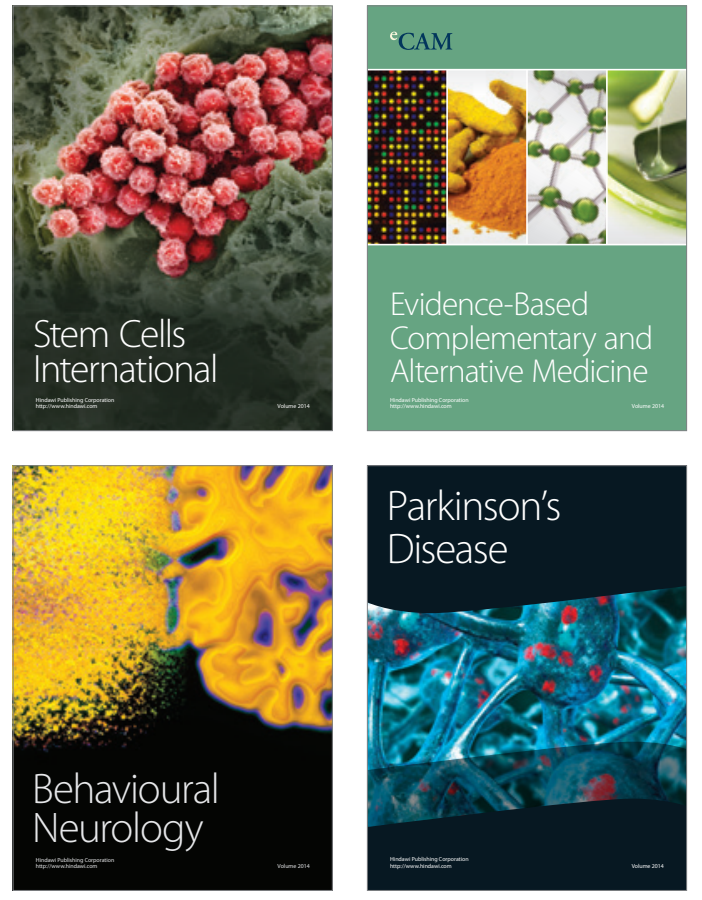
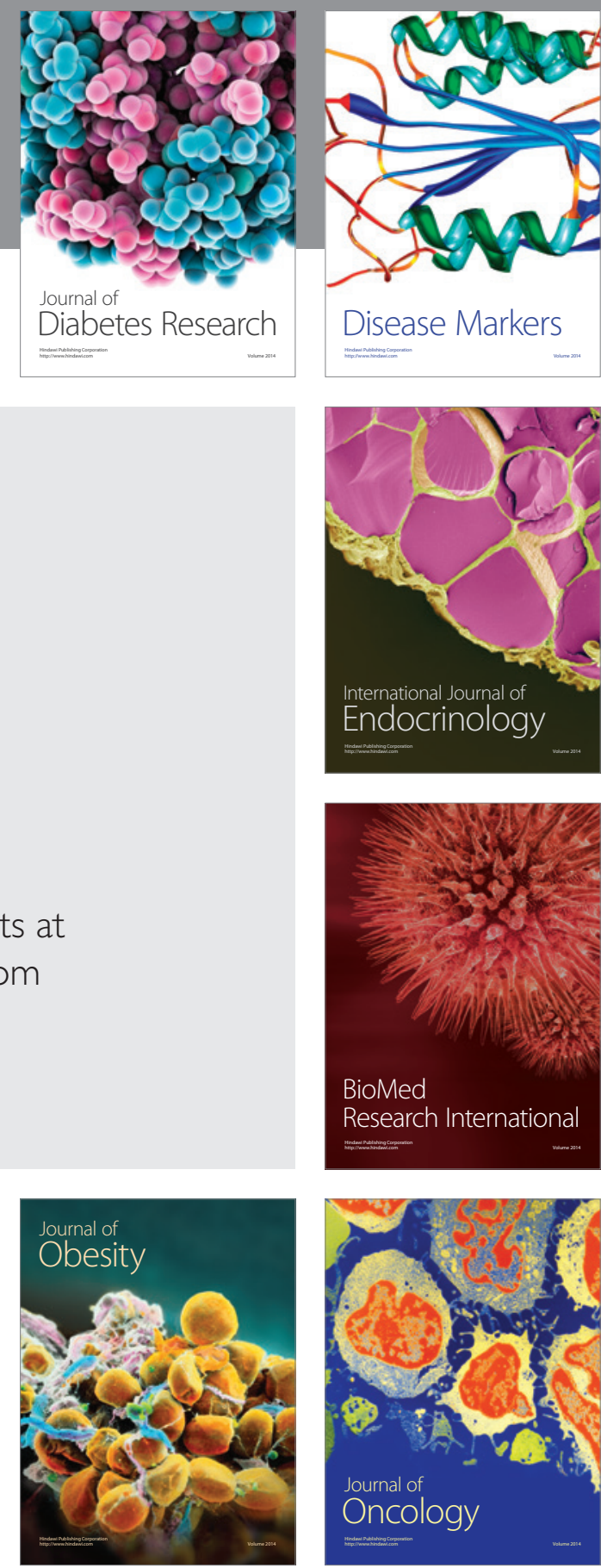

Disease Markers
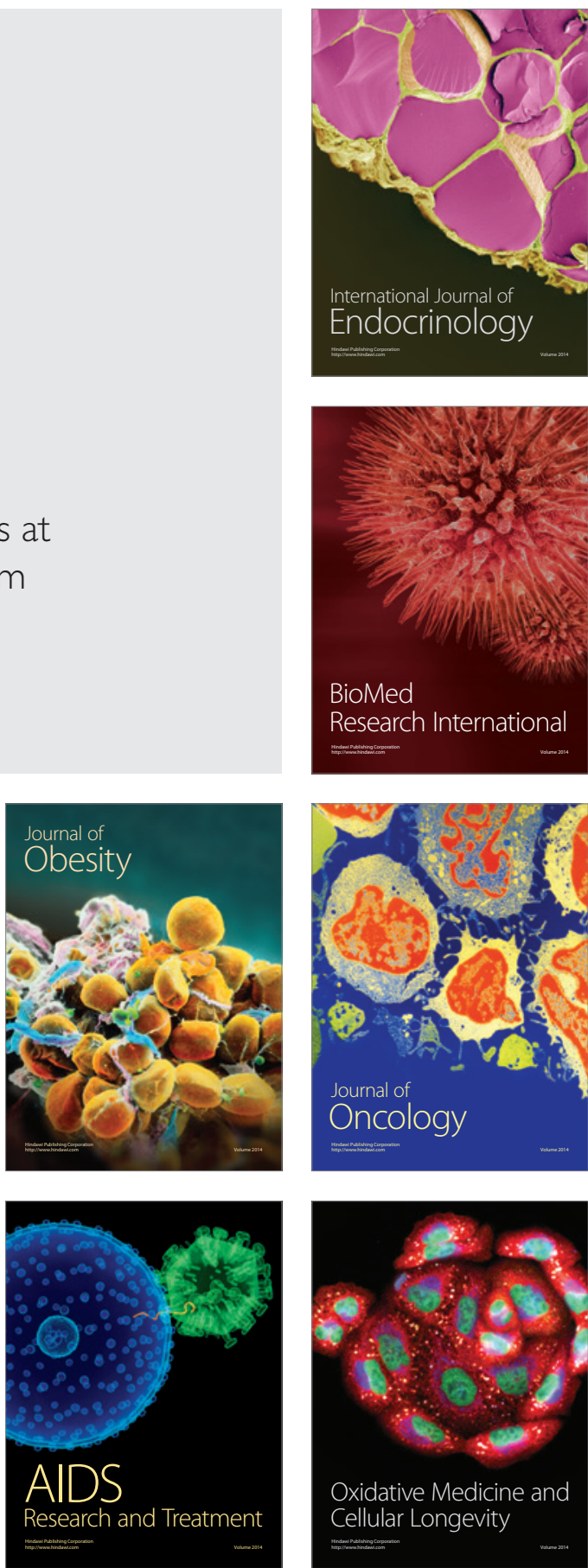